\title{
SYNTHESIS AND COORDINATION BEHAVIOUR OF HYDROXAMATE RESIN WITH VARYING SPACER GROUPS
}

\author{
C. Y. LIU,* M. J. CHEN, N. M. LEE, H. C. HWANG, S. T. JOU and J. C. HSU \\ Department of Chemistry, National Taiwan University, Taipei, Taiwan, Republic of China
}

(Received 15 July 1991 ; accepted 9 October 1991)

\begin{abstract}
Three kinds of chelating resin-containing hydroxamic acid functional groups with varying spacer groups were synthesized. They are acetohydroxamate resin (P-3), glycinohydroxamate resin (P-9) and $\gamma$-aminobutyrohydroxamate resin (P-13). The coordination behaviour of copper(II) ions for these resins was studied with the aid of EPR, IR, electronic spectra and potentiometry. The EPR studies show that the formation of metalresin complexes is $\mathrm{pH}$-dependent. The $g$ value and $A$ values, calculated from the spectral data, indicate that the copper(II) environment could be of oxygen atoms only, as $\mathrm{CuO}_{4}$ species. The electronic spectra along with EPR spectra suggest a square planar environment around the copper(II) in these resin complexes. The bidentate character of the synthesized resin was also inferred from IR spectra. The results derived from EPR, electronic spectra and potentiometry show that P-3 favours intermolecular complexation, and P-9 or P-13 favours intramolecular complexation predominantly.
\end{abstract}

The development of new chelating resins of great sclectivity for some of the toxic heavy metals or for pre-concentration of trace metal ions in the high concentration of electrolyte samples is attractive for both analytical use and their intrinsic interest to coordination chemists. Chelating resin is a kind of polymeric complexing agent, which has been widely used in many applications. ${ }^{1}$ The properties of these systems are mainly governed by complex formation. Most of the time, the application of the synthesized chelating resins are entirely inspired by analogy to the reactions between metal ions and a small model molecule. However, chelating resins exhibit some very particular fealures arising from the fact that ligands are connected on the polymer chain, which greatly limits the analogy with classical complexation between small molecules.

Hydroxamic acids are well known as good extracting agents for a number of metal ions. ${ }^{2}$ They were also successfully used for the colourimetric determination of various metal ions..$^{3-5}$ In the case of certain naturally occurring trihydroxamic acids, the siderochromes, which include the ferrioxamines and the ferrichromes, the stabilities of the iron com-

\footnotetext{
* Author to whom correspondence should be addressed.
}

plexes are exceptional. The cause of these high stabilitics can be attributed not only to the high coordinative power of the hydroxamic acid for iron but also to the number and spacing of the coordinative groups. ${ }^{6}$ Using the naturally occurring trihydroxamic acids as models, some chelating resins with varying spacings between hydroxamate groups, i.e. acetohydroxamate resin (P-3), glycinohydroxamate resin (P-9) and $\gamma$-aminobutyrohydroxamate resin (P-13) were synthesized. The coordination behaviour of copper(II) with these hydroxamic acid resins was studied with the aid of EPR, IR, electronic spectra and potentiometry.

\section{EXPERIMENTAL}

\section{Apparatus}

The IR spectra of the synthesized chelating resins and their metal complexes in $\mathrm{KBr}$, in the range $4000-200 \mathrm{~cm}^{-1}$, were recorded on a Perkin-Elmer 983 IR spectrophotometer. The EPR spectra of the complexes in the solid state at room temperature were recorded on a Bruker ESP 300 spectrometer. The electronic spectra were obtained from the direct 
measurement of light absorption of solid resin complexes. The quartz cell used was the same as that used by Yoshimura, ${ }^{7}$ and the spectra were performed with the Hitachi model U-3200 recording spectrophotometer.

\section{Reagents}

The chemicals used in this investigation were all reagent grade.

\section{Synthesis of the acetohydroxamate resin $(\mathrm{P}-3)^{8}$}

Separate solutions of hydroxylamine hydrochloride $(140 \mathrm{~g})$ in methyl alcohol $\left(720 \mathrm{~cm}^{3}\right)$, and of potassium hydroxide $(112 \mathrm{~g})$ in methyl alcohol $\left(280 \mathrm{~cm}^{3}\right)$, were prepared at the boiling point of the solvent. Both were cooled to $30-40^{\circ} \mathrm{C}$ and potassium hydroxide solution was added, with shaking, to the hydroxylamine solution; any excessive rise of temperature during the addition was prevented by cooling in an ice bath. After all alkali had been added, the mixture was allowed to stand in an ice bath for $5 \mathrm{~min}$ to ensure complete precipitation of potassium chloride. Hydroxylamine solutions thus obtained were used to prepare the chelating resin.

A macroporous cross-linked co-polymer was prepared by the rcaction of acrylonitrile and divinylbenzene by the procedure given in ref. 9 . The hydrolysed product of polyacrylonitriledivinylbenzene co-polymer was prepared. ${ }^{9}$ The carboxylic acid resin was then converted to acetohydroxamate resin by heating a mixture of the resin and hydroxylamine prepared as above under $\mathrm{pH} 8$ 9 at $70^{\circ} \mathrm{C}$ in methyl alcohol for $30 \mathrm{~h}$. The final product was collected by filtration under suction and washed sequentially with water, $0.25 \mathrm{M}$ sulphuric acid, water and acetone.

\section{Synthesis of the glycinohydroxamate resin $(\mathrm{P}-9)^{10}$}

Carboxylic acid resin $(20 \mathrm{~g})$ obtained by the above procedures was placed in the flask containing petroleum ether $\left(150 \mathrm{~cm}^{3}\right)$, to which thionyl chloride $\left(20 \mathrm{~cm}^{3}\right)$ was added dropwise. The resultant mixture was reacted under nitrogen gas at $80^{\circ} \mathrm{C}$ for $12 \mathrm{~h}$. Glycine ethyl ester ( $25 \mathrm{~g}$ ) was then added and the mixture reacted at $60^{\circ} \mathrm{C}$ for $40 \mathrm{~h}$. The product was collected by filtration under suction and washed sequentially with water and acetone. Half molar hydrochloride free hydroxylamine and $25 \mathrm{~g}$ of the above product were reacted under similar conditions and collected in the same manner as those of P-3.

\section{Synthesis of the $\gamma$-aminobutyrohydroxamate resin $(\mathrm{P}-13)^{11}$}

Carboxylic acid resin $(20 \mathrm{~g})$ obtained by the above procedures was placed in a flask containing petroleum ether $\left(20 \mathrm{~cm}^{3}\right)$ at a temperature below $0^{\circ} \mathrm{C}$. Thionyl chloride $\left(26 \mathrm{~cm}^{3}\right)$ was then added dropwise. The reaction tempcrature was raised to $80^{\circ} \mathrm{C}$ and allowed to react for $18 \mathrm{~h}$. The resultant mixture was vacuum-evaporated to distill the petroleum ether and excess thionyl chloride out. Dioxane $\left(20 \mathrm{~cm}^{3}\right)$ and $\gamma$-aminobutyric acid $(27 \mathrm{~g})$ were added to the above product, and reacted at $70^{\circ} \mathrm{C}$ for $24 \mathrm{~h}$. After the colour of the resin changed from yellow to pink, the product was collected by filtration under suction and washed sequentially with water and acetone. The product $(20 \mathrm{~g})$ was then reacted with half molar hydrochloride free hydroxylamine under $\mathrm{pH} 8-9$ at $70^{\circ} \mathrm{C}$ for $18 \mathrm{~h}$ in methyl alcohol. The final product was washed sequentially with $0.25 \mathrm{M}$ sulphuric acid, water and acetone.

\section{Preparation of metal complexes}

Dry resin $(\mathrm{ca} 300 \mathrm{mg}$ ) was added to each polyethylene bottle $\left(100 \mathrm{~cm}^{3}\right)$ containing either 0.04 or $0.0004 \mathrm{M}$ metal ion in deionized water $\left(25 \mathrm{~cm}^{3}\right)$. The $\mathrm{pH}$ of the solution was adjusted to the required value with perchloric acid or sodium hydroxide. The mixture was stirred for $24 \mathrm{~h}$ at $25 \pm 0.1^{\circ} \mathrm{C}$. After equilibration, the $\mathrm{pH}$ value was measured. The solution was then filtered. The metal ion in solution was measured by EDTA titration or spectrophotometry. The wet resin phase was dried in a vacuum oven and subjected to IR and EPR spectral measurements.

\section{Potentiometric titrations}

Acid dissociation constant. Since this is a heterogeneous system, the equilibrium cannot be obtained as fast as that in the homogeneous system. The potentiometric titration could not then be carried out continuously in a single vessel, rather in a batch-by-batch method. In this investigation, at least 14 samples of each kind of resin $(0.2 \mathrm{~g})$ were accurately weighed and placed respectively in each PE bottle $\left(100 \mathrm{~cm}^{3}\right)$. Aqueous solutions containing various amounts of $0.1 \mathrm{M}$ sodium hydroxide were made to ionic strengths of 0.1 or $0.5 \mathrm{M}$ with potassium chloride and brought to $50 \mathrm{~cm}^{3}$ total volume. The solutions were added to the PE bottle containing the resin. The mixture was stirred for 4 $\mathrm{h}$ at $25 \pm 0.1^{\circ} \mathrm{C}$. After equilibration, the $\mathrm{pH}$ was monitored by a Radiometer PHM 61 pH meter with 
a GK $2401 \mathrm{C}$ combined electrode. Electrodes were standardized immediately before measurement with pH 4.01 and 6.86 buffer solutions.

Stability constant. The apparatus and procedures of these experiments were identical to those described in the previous section with the exception that in each case either a $3: 1$ or $1: 1$ metal resinligand ratio of metal salt was added to the resin solution. The total volume was $50 \mathrm{~cm}^{3}$.

\section{RESULTS AND DISCUSSION}

The reaction between acrylate-divinylbenzene copolymer and either glycine or $\gamma$-aminobutyric acid gave the corresponding intermediates. The products were then treated with hydroxylamine to give the acetohydroxamate resin (synthesized directly from acrylate-divinylbenzene co-polymer and hydroxylamine), glycinohydroxamate resin and $\gamma$-aminobutyrohydroxamate resin. Depending upon which amino acid was used in the reaction, the spacers between hydroxamic acid groups of the resin were three, nine or 13 atoms, respectively, so that the resins were designated as $\mathrm{P}-3, \mathrm{P}-9$ or P-13 by simplification.

The reaction steps were as follows: hydrogen carbonate. The analytical and physical data of the synthesized resin are listed in Table 1.

Copper(II) displays a wide variety of coordination geometries in its many salts and complexes. Its common coordination numbers are four, five and six. Hydroxamic acids are important analytical reagents. Hydroxamic acid and its metal complexes were also found to play an important role in living systems. ${ }^{13}$ In spite of the great interest in hydroxamic acid and metal hydroxamates, studies of hydroxamate resin are rather scarce. Needless to say, studies of the coordination behaviour of metal-resin complexes are even fewer. There has been considerable interest recently in the EPR spectra of metal-resin complexes. ${ }^{14-16}$ In this study, the EPR spectra of the synthesized resin copper complexes will be chosen for investigation. Basically, the interpretation of the EPR spectrum of an isolated transition metal ion yields values for two types of parameter : the spectroscopic splitting constants ( $g$-values) and the hyperfine coupling constants ( $A$ values). These parameters are affected by the presence of ligands around the central metal ion.

acrylonitrile + divinylbenzene $\stackrel{\alpha, \alpha \text {-azobisisobutyronitrile, sodium lauryl sulphate }}{\longrightarrow}$ co-polymer $(\mathrm{R}-\mathrm{C} \equiv \mathrm{N})$

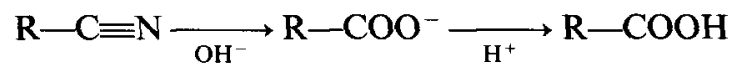

(a)

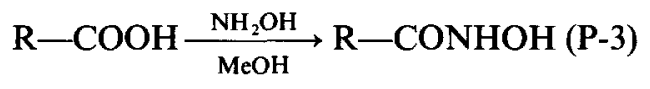

(b)

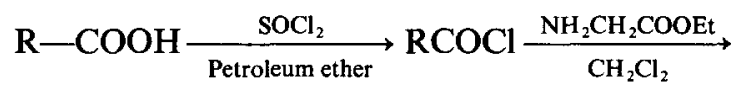

$\mathrm{RCONHCH}_{2} \mathrm{COOEt} \underset{\mathrm{MeOH}}{\stackrel{\mathrm{NH}_{2} \mathrm{OH}}{\longrightarrow}} \mathrm{RCONHCH}_{2} \mathrm{CONHOH}(\mathrm{P}-9)$

(c)

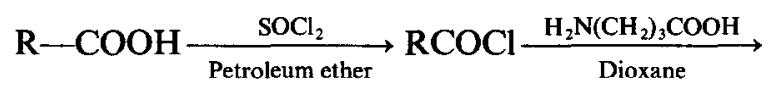

$$
\mathrm{RCONH}\left(\mathrm{CH}_{2}\right)_{3} \mathrm{COOH} \underset{\mathrm{MeOH}}{\stackrel{\mathrm{NH}_{2} \mathrm{OH}}{\longrightarrow}} \mathrm{RCONH}\left(\mathrm{CH}_{2}\right)_{3} \mathrm{CONHOH}(\mathrm{P}-13) .
$$

The synthesized resins were characterized by elementary analysis, IR spectra, hydrogen and metal capacity. The detailed procedures are given in ref. 12. The number of functional groups incorporated for each kind of resin was determined by acid-base titration. Since there are unreacted carboxylate groups in the final product the hydrogen capacity, including the replaceable hydrogen of the unrcacted carboxylate group and that of hydroxamate group, was determined by sodium hydroxide. While for the functionality, only the amount of hydroxamate group was determined by sodium
The $\mathrm{pH}$-dependence of the sorption behaviour of P-3, P-9 and P-13 toward copper(II) was tested by the batch equilibrium method. Samples were run both in excess metal ion concentration or in excess resin-ligand concentration. After equilibration, the amount of metal ion in the solution or in the resin phase was determined to calculate the metal capacity from the former condition and distribution coefficient from the latter one. The EPR spectra of $\mathrm{P}-3, \mathrm{P}-9$ and $\mathrm{P}-13$ as a function of $\mathrm{pH}$ either in excess metal ions or in excess resin-ligand were mea- 
Table 1. Characteristics of acetohydroxamate resin (P-3), glycinohydroxamate resin (P-9) and $\gamma$-aminobutyrohydroxamate resin (P-13)

\begin{tabular}{lccc}
\hline & P-3 & P-9 & P-13 \\
\hline Cross linking (\%) & 8 & 8 & 8 \\
Particle size (mesh) & $60-100$ & $60-100$ & $60-100$ \\
E. A. (\%) C & 54.87 & 53.90 & 45.85 \\
H & 6.43 & 7.03 & 6.86 \\
N & 5.97 & 9.24 & 6.83 \\
Functionality (mmol g $\left.{ }^{-1}\right)^{a}$ & 2.48 & 1.76 & 2.21 \\
Hydrogen capacity (mmol g g $\left.^{-1}\right)^{a}$ & 6.72 & 4.47 & 6.03 \\
Copper capacity (mmol g (m) $^{-1}$ & 2.57 & 1.90 & 2.00 \\
\hline
\end{tabular}

${ }^{a}$ Mean of three determinations.

sured at room temperature. These spectra were also recorded at $77 \mathrm{~K}$ but they do not show a better resolution than at room temperature. The $g_{\perp}$ and $g_{\|}$values, calculated from the spectral data, are given in Tables 2 and 3. All of the results for P-3, P-9 and P-13 showed that $g_{\|}>g_{\perp}$, which is charac-

Table 2. The parameters of the EPR spectra for copper(II)-resin complexes (metal ion excess)

(a) Acetohydroxamate resin

\begin{tabular}{ccccc}
\hline & $\begin{array}{c}\text { Capacity } \\
\text { pH }\end{array}$ & & & $\begin{array}{c}\Delta H p p \\
(\mathrm{mmol} \mathrm{g})\end{array}$ \\
\hline 2.01 & 0.31 & 2.066 & - & 100 \\
3.11 & 0.82 & 2.085 & - & 183 \\
3.94 & 1.83 & 2.100 & - & 260 \\
5.01 & 2.57 & 2.102 & - & 267 \\
\hline
\end{tabular}

(b) Glycinohydroxamate resin

\begin{tabular}{|c|c|c|c|c|c|}
\hline $\mathrm{pH}$ & $\begin{array}{c}\text { Capacity } \\
\left(\mathrm{mmol} \mathrm{g}^{-1}\right)\end{array}$ & $g_{\perp}$ & $g_{\sharp}$ & $A(\mathrm{G})$ & $\begin{array}{c}\Delta H p p \\
(\mathrm{G})\end{array}$ \\
\hline 1.70 & 0.10 & 2.072 & 2.316 & 145 & 63 \\
\hline 2.05 & 0.15 & 2.073 & 2.324 & 145 & 80 \\
\hline 2.43 & 0.55 & 2.078 & 2.343 & - & 81 \\
\hline 4.32 & 1.80 & 2.140 & - & - & 290 \\
\hline 4.50 & 1.90 & 2.146 & - & - & 285 \\
\hline
\end{tabular}

(c) $\gamma$-Aminobutyrohydroxamate resin

\begin{tabular}{cccccc}
\hline \multicolumn{3}{c}{ Capacity } \\
$\mathrm{pH}$ & $\left(\mathrm{mmol} \mathrm{g}^{-1}\right)$ & $g_{\perp}$ & $g_{\|}$ & $A(\mathrm{G})$ & $\begin{array}{c}\Delta H p p \\
(\mathrm{G})\end{array}$ \\
\hline 1.70 & 0.06 & 2.071 & 2.317 & 143 & 60 \\
2.79 & 0.88 & 2.094 & 2.300 & 159 & 240 \\
3.59 & 1.08 & 2.127 & - & - & 261 \\
4.07 & 1.48 & 2.130 & - & - & 267 \\
\hline
\end{tabular}

Table 3. The parameters of the EPR spectra for copper(II)-resin complexes (resin ligand excess)

(a) Acetohydroxamate resin

\begin{tabular}{cccccc}
\hline $\mathrm{pH}$ & $\log D$ & $g_{\perp}$ & $g_{\|}$ & $A(\mathrm{G})$ & $\begin{array}{c}\Delta H p p \\
(\mathrm{G})\end{array}$ \\
\hline 2.65 & 1.44 & 2.069 & 2.302 & 135 & 80 \\
2.80 & 1.66 & 2.072 & 2.302 & 141 & 79 \\
2.93 & 1.83 & 2.077 & 2.314 & 123 & 142 \\
3.07 & 2.02 & 2.076 & 2.302 & 135 & 156 \\
3.22 & 2.15 & 2.075 & - & - & 173 \\
3.39 & 2.28 & 2.074 & - & - & 184 \\
3.59 & 2.42 & 2.074 & - & - & 184 \\
3.80 & 2.55 & 2.073 & - & - & 182 \\
4.01 & 2.71 & 2.072 & - & - & 182 \\
4.22 & 2.89 & 2.074 & - & - & 188 \\
\hline
\end{tabular}

(b) Glycinohydroxamate resin

\begin{tabular}{cccccc}
\hline $\mathrm{pH}$ & $\log D$ & $g_{\perp}$ & $g_{\|}$ & $A(\mathrm{G})$ & $\begin{array}{c}\Delta H p p \\
(\mathrm{G})\end{array}$ \\
\hline 1.11 & $<1$ & 2.060 & - & - & 77 \\
1.90 & 1.46 & 2.072 & 2.317 & 148 & 65 \\
2.44 & 1.56 & 2.071 & 2.314 & 152 & 60 \\
3.28 & 3.77 & 2.073 & 2.321 & 148 & 62 \\
3.94 & 3.87 & 2.073 & 2.323 & 144 & 60
\end{tabular}

(c) $\gamma$-Aminobutyrohydroxamate resin

\begin{tabular}{cccccc}
\hline $\mathrm{pH}$ & $\log D$ & $g_{\perp}$ & $g_{\|}$ & $A(\mathrm{G})$ & $\begin{array}{c}\Delta H p p \\
(\mathrm{G})\end{array}$ \\
\hline 1.91 & 0.74 & 2.053 & - & - & 88 \\
2.78 & 1.79 & 2.066 & 2.317 & 140 & 62 \\
3.20 & 2.00 & 2.067 & 2.312 & 147 & 61 \\
\hline
\end{tabular}

teristic of tetragonal or square planar geometry, ${ }^{17}$ and $g$ being more than 2.3 indicates the ionic character of the metallic ligand bond. ${ }^{18}$ At $\mathrm{pH}$ below 3 medium, most of the copper-resin complexes studied showed $g_{\|}$components in its EPR spectrum. These facts suggest a very slow motion of copper ion. While at $\mathrm{pH}$ above 3 , few or no $g_{\|}$components show. From this comparison, it can be said that the mobility of copper ions decreases as the $\mathrm{pH}$ decreases, since the resin ligand is in excess in these situations. In case of highly loaded resins (metal ion excess), only P-9 and P-13 show $g_{\|}$components at $\mathrm{pH}$ below 3. In addition, one very broad signal appears with an average $g$ value of 2.14. This must be caused by weak copper-copper interactions, resulting in the disappearance of the hyperfine structure in the EPR spectrum for both P-9 and P13 resin. While this phenomenon for P-3 is some- 
Table 4. Comparison of the $g$ values of copper-resin complexes

\begin{tabular}{lll}
\hline \multicolumn{1}{c}{ Resin } & $g_{\perp}$ & $g_{\|}$ \\
\hline Acetohydroxamate & 2.07 & 2.30 \\
Glycinohydroxamate & 2.07 & 2.31 \\
y-Aminobutyrohydroxamate & 2.07 & 2.31 \\
Dowex A-1 & 2.07 & 2.29 \\
Unicellex UR-50 & 2.08 & 2.30 \\
\hline
\end{tabular}

what different from that for P-9 and P-13, the $g$ values for P-3 appear to be slightly lower (2.10). The variance could be attributed to metal-ligand complexation among P-3 resins, which may be predominantly an intermolecular complexation, while that among P-9 and P-13 resin may be predominantly intramolecular complexation. ${ }^{19}$ By comparison the EPR spectrum of copper ions on hydroxamate resin with those of copper ions on Dowex A-1 and Unicellex UR-50 shows that the $g$ and $A$ values are consistent among them, ${ }^{14,20}$ as shown in Table 4. It can be concluded that the $\mathrm{CuO}_{4}$ model can be well explained in these investigations.

The colour and the absorption maxima of the electronic spectra of the resin-copper complexes together with some reference compounds are shown as Table 5. The electronic spectra for these resin complexes involve two intense bands and one shoulder and in this respect, correspond to the reported spectra of $\mathrm{Cu}(\mathrm{BHA})$ and $\mathrm{Cu}(\mathrm{MAHA})_{2}$ with square planar geometry, ${ }^{21}$ where BHA is benzohydroxamic acid and MAHA is N-methylhydroxamic acid. The peaks with a higher wavenumber could be assigned from a charge-transfer state and the peaks with a lower wavenumber to-

Table 5. Electronic spectra of copper(II) in hydroxamate resin and some reference compounds

\begin{tabular}{|c|c|c|c|c|c|}
\hline Complex & Colour & Obser & $\begin{array}{c}\text { rved abso } \\
\text { bands } \\
v\left(\mathrm{~cm}^{-1}\right)\end{array}$ & rption & $\underset{\left(\mathrm{cm}^{-1}\right)}{D q}$ \\
\hline Cu-P-3 & green & 24390 & 15197 & 14084 & $7 \quad 1408$ \\
\hline $\mathrm{Cu}-\mathrm{P}-9$ & green & 21978 & 15360 & 13292 & 21329 \\
\hline $\mathrm{Cu}-\mathrm{P}-13$ & green & 21052 & 15384 & 13292 & $2 \quad 1329$ \\
\hline $\mathrm{Cu}(\mathrm{BHA})^{a}$ & blue green & 25000 & 15900 & 12700 & \\
\hline $\mathrm{Cu}(\mathrm{MAHA})_{2}^{a}$ & deep blue & $\begin{array}{r}25970 \\
(23200\end{array}$ & $\begin{array}{c}19230 \\
(17200)\end{array}$ & $\begin{array}{c}16070 \\
(14920)\end{array}$ & \\
\hline
\end{tabular}

\section{${ }^{a}$ See ref. 21.}

P-3: acetohydroxamate resin; P-9; glycinohydroxamate resin; P-13: $\gamma$-aminobutyrohydroxamate resin; BHA : benzohydroxamic acid; MAHA : $\mathbf{N}$-methylhydroxamic acid. gether with the shoulder may be assigned as the $d-$ $d$ transition for these copper-resin complexes. The $10 \mathrm{Dq}$ value is slightly lower than that for the monomeric hydroxamate complexes. The above results also show that the coordination behaviour of P-9 is similar to that of P-13 and somewhat different from that of P-3.

Peak positions and assignments of the IR spectra of copper-resin complexes are given in Table 6. In the IR spectrum of the resin (P-3), peaks centred at $3188(-\mathrm{NHOH}), 1687(-\mathrm{C}=\mathrm{O}$ of $-\mathrm{CONH})$, 1453, 941 (amide II band), 1403 (amide III band) and $618 \mathrm{~cm}^{-1}(-\mathrm{N}-\mathrm{C}=\mathrm{O}$ bending) indicated the presence of the hydroxamate group. Peaks at $\mathbf{1 7 3 6}$ $(-\mathrm{C}=\mathrm{O}$ of $-\mathrm{COOH})$ and $1188 \mathrm{~cm}^{-1}$ were assigned to the presence of the unreacted carboxylate groups. In the IR spectrum of the resin (P9), peaks centred at 3333, $3227(-\mathrm{NHOH}), 1664$ ( $-\mathrm{C}=\mathrm{O}$ of $-\mathrm{CONH}$ ), 1453 (amide II band) and $1401 \mathrm{~cm}^{-1}$ (amide III band) indicated the presence of the hydroxamate group. Peaks at $1717(-\mathrm{C}=\mathrm{O}$ of $-\mathrm{COOH}), 1225$ and $1164 \mathrm{~cm}^{-1}$ were assigned to the presence of unreacted carboxylate groups. In the IR spectrum of the resin (P-13), peaks centred at $3340,3213(-\mathrm{NHOH}), 1686(-\mathrm{C}=\mathrm{O}$ of - CONH), 1446, 936 (amide II band), 1373 (amide III band) and $533 \mathrm{~cm}^{-1}$ ( $-\mathrm{C}=\mathrm{O}$ bending) indicated the presence of the hydroxamate group. The spectrum also showed the presence of some unreacted carboxylate groups. In the metal-resin complexes, vibrational evidence for oxygen-coordination of the hydroxamate groups concerning $v(\mathrm{C}-\mathrm{O})$ and $v(\mathrm{~N}-\mathrm{O})$ are obvious. Coordination causes these peaks to move to higher wavenumbers as shown in Table 6 . The broad $v(\mathrm{OH})$ around $3660-3080 \mathrm{~cm}^{-1}$ is attributed to the hydrogen bonding of the coordinated water molecule with the oxygen atom of the hydroxamate group. If any hydroxamate groups remain free, a medium intensity band can be observed at the free hydroxamate group's wavenumber. Therefore, the metal-resin complexes' assignments may be complicated by the presence of bound and free hydroxamate groups.

Investigation of the stability of copper chelates of these resins possibly makes an interesting comparison with chelation tendencies of the corresponding monomeric hydroxamic acid. The titration curves of either P-3, P-9 and P-13 or its metal-resin complexes are shown in Figs 1-3. The acid dissociation constants of these resins and the stability constants of the resin-metal complexes were calculated by a modification of Bjerrum's method. ${ }^{22}$ The 3:1 metal chelate titration curves were used for calculation of the stability constants. The results are shown as Table 7. By comparison with data of the corresponding monomers, aceto- 
Table 6. Principal IR absorption bands of P-3, P-9 and P-13 chelating resin and its metal complexes

\begin{tabular}{lcccccc}
\hline & P-3 & P-3-Cu & P-9 & P-9-Cu & P-13 & P-13-Cu \\
\hline- NHOH & \multirow{2}{*}{3188} & \multirow{2}{*}{3188} & 3333 & 3370 & 3340 & 3429 \\
& & & 3227 & 3224 & 3213 &
\end{tabular}<smiles>CC(=O)O</smiles>

$\begin{array}{llll}1736 & 1722 & 1717 & 1729\end{array}$<smiles>CC(N)=O</smiles>

Amide II band $-\mathrm{COO}^{-}$asym. str., NH def.

Amide III band

\begin{tabular}{lrrrrrr}
$-\mathrm{COO}^{-}$sym. str. & 1403 & 1409 & 1401 & 1430 & 1373 & 1407 \\
$-\mathrm{C}-\mathrm{O}$ str. & 1188 & 1213 & 1225 & 1236 & 1219 & 1210 \\
$\mathrm{~N}-\mathrm{C}=$ O bending & 618 & 609 & & & 533 & 572 \\
\hline
\end{tabular}

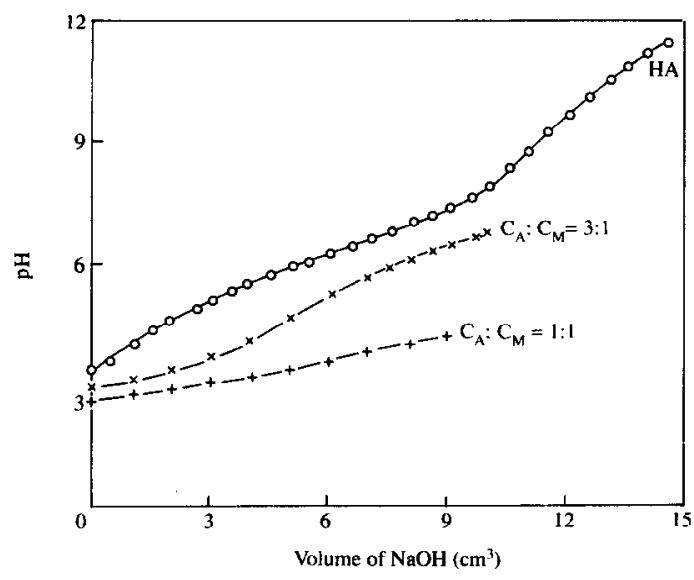

Fig. 1. Titration curves of acetohydroxamate resin and its metal complexes. Volume of solution: $25 \mathrm{~cm}^{3}$; amount of resin: $0.2 \mathrm{~g}$; ionic strength: $0.5 \mathrm{M} ; T: 25 \pm 0.1^{\circ} \mathrm{C}$; $[\mathrm{NaOH}]: 0.1 \mathrm{M}$.

hydroxamic acid ${ }^{23}$ and glycinohydroxamic acid, ${ }^{24,25}$ both the acid dissociation constants and the stability constants are rational. Since no corresponding monomer of $\gamma$-aminobutyrohydroxamate resin can be obtained as a model for comparison, judgement can be approximation only. Although the stability constants of metalresin complexes are larger than those of the corresponding monomer, they reflect the usual trend for a normal system and follow the Irving-

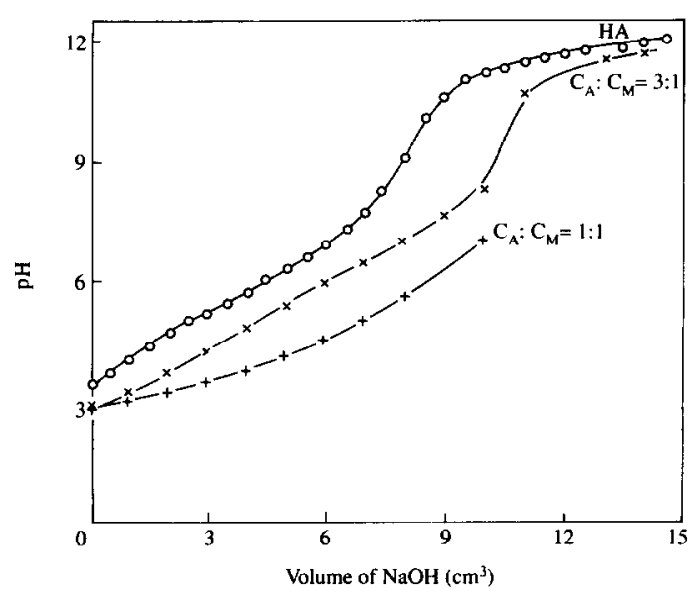

Fig. 2. Titration curves of glycinohydroxamate resin and its metal complexes. Volume of solution: $25 \mathrm{~cm}^{3}$; amount of resin: $0.2 \mathrm{~g}$; ionic strength: $0.5 \mathrm{M} ; T: 25 \pm 0.1^{\circ} \mathrm{C}$; $[\mathrm{NaOH}]: 0.1 \mathrm{M}$.

Williams sequence, ${ }^{26}$ viz. $\mathrm{Fe}>\mathrm{Cu}>\mathrm{Pb}>\mathrm{Zn}>$ $\mathrm{Ni}>\mathrm{Co}>\mathrm{Cd}>\mathrm{Mn}$. However, the results showed that the variation of stability constants among P-3, $P-9$ and P-13 is not as great as that expected from the spacer. Adequate complexation must occur in the P-3 system. It is suggested that the intermolecular complexation reaction may exist among P-3 rcsins and optimum for high complex stability, while the spacer between hydroxamic acids for both P-9 and P-13 appeared to be optimum for the intra- 


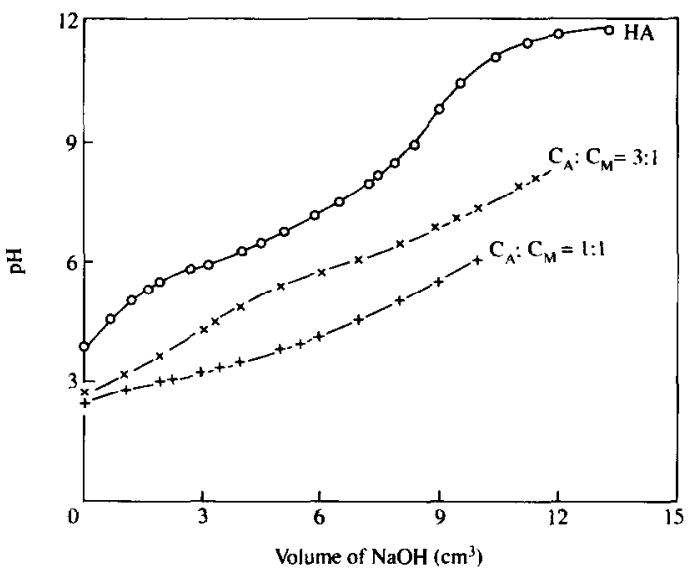

Fig. 3. Titration curves of $\gamma$-aminobutyrohydroxamate resin and its metal complexes. Volume of solution : 25 $\mathrm{cm}^{3}$; amount of resin: $0.2 \mathrm{~g}$; ionic strength : $0.1 \mathrm{M} ; T$ : $25 \pm 0.1^{\circ} \mathrm{C} ;[\mathrm{NaOH}]: 0.1 \mathrm{M}$.

molecular complexation reaction. These phenomena correspond to those from the EPR study. The complexation types of these resins assigned tentatively in this paper are shown in Scheme 1.

\section{CONCLUSION}

Precise determination of the coordination behaviour of the functional group towards metal ions is essential for the further development of a metal ion-selective ion-exchange resin. The work gives fundamental information on use as agents for heavy metal ion separation and recovery in solution, or as

Table 7. Equilibrium constants

\begin{tabular}{|c|c|c|}
\hline Metal complex & Equilibrium & $\log K_{\mathrm{f}}$ \\
\hline $\mathrm{P}-3-\mathrm{H}^{a}$ & $\mathrm{HL} / \mathrm{H} \cdot \mathrm{L}$ & 9.95 \\
\hline \multirow[t]{2}{*}{ P-3-Cu ${ }^{a}$} & $\mathrm{ML} / \mathbf{M} \cdot \mathrm{L}$ & 8.90 \\
\hline & $\mathrm{ML}_{2} / \mathbf{M} \cdot \mathrm{L}^{2}$ & 8.50 \\
\hline $\mathrm{P}-9-\mathrm{H}^{a}$ & $\mathrm{HL} / \mathrm{H} \cdot \mathrm{L}$ & 10.00 \\
\hline \multirow[t]{2}{*}{ P-9-Cu ${ }^{a}$} & $\mathrm{ML} / \mathrm{M} \cdot \mathrm{L}$ & 8.91 \\
\hline & $\mathrm{ML}_{2} / \mathbf{M} \cdot \mathrm{L}^{2}$ & 8.60 \\
\hline P-13-H ${ }^{b}$ & $\mathbf{H L} / \mathbf{H} \cdot \mathbf{L}$ & 10.50 \\
\hline \multirow[t]{2}{*}{ P-13-Cu } & $\mathrm{ML} / \mathrm{M} \cdot \mathrm{L}$ & 8.90 \\
\hline & $\mathrm{ML}_{2} / \mathbf{M} \cdot \mathrm{L}^{2}$ & 8.20 \\
\hline Acetohydroxamic acid (AHA) ${ }^{c}$ & $\mathrm{HL} / \mathrm{H} \cdot \mathrm{L}$ & 9.36 \\
\hline $\mathrm{AHA}-\mathrm{Cu}^{c}$ & $\mathbf{M L} / \mathbf{M} \cdot \mathbf{L}$ & 7.90 \\
\hline 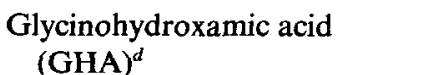 & $\mathrm{HL} / \mathrm{H} \cdot \mathrm{L}$ & 9.11 \\
\hline $\mathrm{GHA}-\mathrm{Cu}^{d}$ & $\mathbf{M L}_{2} / \mathbf{M} \cdot \mathbf{L}^{2}$ & 16.89 \\
\hline
\end{tabular}

${ }^{a} \mathrm{I}=0.5 \mathrm{M} \mathrm{KCl}, T=25 \pm 0.1^{\circ} \mathrm{C}$.

${ }^{b} \mathrm{I}=0.1 \mathrm{M} \mathrm{KCl}, T=25 \pm 0.1^{\circ} \mathrm{C}$.

${ }^{c}$ Ref. 23.

${ }^{d}$ Refs 24 and 25.

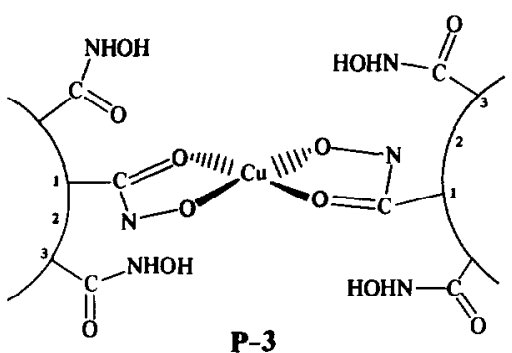
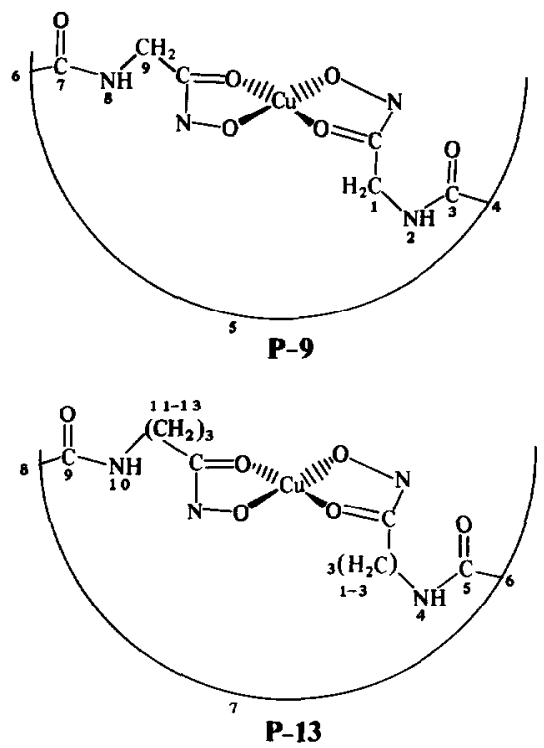

Scheme 1. Suggested structures for acetohydroxamate resin (P-3), glycinohydroxamate resin (P-9) and $\gamma$-aminobutyrohydroxamate resin (P-13) copper complexes. 1, 2, $3,4, \ldots$ represents the number of atoms between two hydroxamate groups in the synthesized resin.

the stationary phase of ligand exchange chromatography.

Acknowledgements-The financial support for this study by the National Science Council of the Republic of China is gratefully acknowledged. The authors also gratefully acknowledge Dr S. H. Chien, Professor of Chemistry, National Taiwan University, for the helpful discussion in EPR studies.

\section{REFERENCES}

1. S. K. Sahni and J. Reedijk, Coord. Chem. Rev. 1984, $59,1$.

2. A. K. Majumdar, N-Benzoylphenylhydroxylamine and its Analogues. Pergamon Press, New York (1972).

3. J. Stary, The Solvent Extraction of Metal Chelates. Pergamon Press, New York (1964).

4. C. C. Chappelow and J. F. Engel, US Patent $3,825,585$ (1974). 
5. E. B. Sandell and H. Onishi, Photometric Determination of Traces of Metals, 4th edn. John Wiley \& Sons, New York (1978).

6. G. Anderegg, F. L'Eplattenier and G. Schwarzenbach, Helv. Chim. Acta 1963, 46, 1409.

7. K. Yoshimura and S. Ohashi, Talanta 1978, 25, 103.

8. C. Y. Liu and P. J. Sun, Fresenius $Z$. Analyt. Chem. $1986,325,553$.

9. C. Y. Liu and P. J. Sun, Analyt. Chim. Acta 1981, 132, 187.

10. H. C. Hwang, Master Thesis, National Taiwan University, ROC (1990).

11. N. M. Lee, Masters Thesis, National Taiwan University, ROC (1990).

12. C. Y. Liu, H. T. Chang and C. C. Hu, Inorg. Chim. Acta 1990, 172, 151.

13. G. L. Eichhorn, Inorganic Biochemistry, Vol. 1. Elsevier Scientific Publishing Co. Inc., New York (1977).

14. K. Umezawa and T. Yamabe, Bull. Chem. Soc. Japan $1972,45,56$.

15. P. J. Hoek and J. Reedijk, J. Inorg. Nucl. Chem. $1979,41,401$.
16. A. Nakashima, T. Isobe and T. Tarutani, Bull. Chem. Soc. Japan 1982, 55, 1811.

17. C. J. Ballhausen, Intruduction to Ligand Field Theory, p. 134. McGraw-Hill, New York (1962).

18. D. Kivelson and R. Neiman, J. Chem. Phys. 1961, 35, 149.

19. A. Winston and D. Kirchner, Macromolecules 1978, $11,597$.

20. C. Heitner-Wirguin and R. Cohen, Inorg. Chim. Acta $1969,3 / 4,647$.

21. D. A. Brown, D. McKeith and W. K. Glass, Inorg. Chim. Acta 1979, 35, 5.

22. J. Bjerrum, Metal Amine Formation in Aqueous Solution. P. Haase and Son, Copenhagen (1941).

23. A. E. Martell and R. M. Smith, Critical Stability Constants, Vol. 1. Plenum Press, New York (1974).

24. E. B. Paniago and S. Carvalho, Inorg. Chim. Acta 1984, 92, 253.

25. B. Kurzak, D. Kroczewska, J. Jezierska and M. H. Koralewicz, Trans. Met. Chem. 1988, $13,297$.

26. A. E. Martell and M. Calvin, Chemistry of the Metal Chelate Compounds. Prentice-Hall, Inc., Englewood Cliffs, New Jersey (1952). 